\title{
Medio-lateral inclination of proximal and distal articular surface of the radius
}

\author{
Ahmed Al-Imam ${ }^{1,2}$ \\ ${ }^{1}$ Doctorate Student (PhD in Medicine), Department of Postgraduate Medicine, School of Life and Medical Sciences, \\ University of Hertfordshire, United Kingdom, '2Lecturer and Researcher, Department of Anatomy and Cellular Biology, \\ Faculty of Medicine, University of Baghdad, Iraq
}

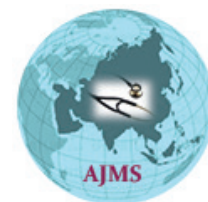

A B S TR A C T

Background: The radius, also known as the radial bone, is the shorter of the two bones of the forearm. It has proximal and distal articulations with the humerus, ulna, and carpal bones. It is almost universally present, as a skeletal blueprint, in eachtetrapod's forelimb. The detailed morphometry of radius, has not been fully explored. Specifically, the inclination of its proximal and distal articular surfaces, which can be affected in many pathologies including: fractures-dislocations, joint's degenerations, tumors, dystrophic calcifications, and pathologic deposits. Aims and Objectives: To derive a statistical inference concerning the inclination of the proximal and distal articular surface of radius. Materials and Methods: In a sample of 30 dry specimens of human radial bone (radius), measurements were done to derive statistical inference concerning: the inclination of proximal and distal articular surfaces (P and D), length of radius (L), mid-point thickness $(T)$, length of head of radius $(H L)$. Materials used for measurements included: electronic Vernier, digital inclinometer, and a tape measure. The most challenging parameter to be measured, was the inclination of articular surfaces, which required multiple reference points: at the interosseous border of radius, proximal and distal ends of radius. Results: The mean values (+/- standard deviation) were: $22.23+/-1.89 \mathrm{~cm}$ (L) $1.43+/-0.2 \mathrm{~cm}(\mathrm{~T}), 0.95+/-0.135 \mathrm{~cm}(\mathrm{HL}), 6.283+/-3.253(\mathrm{P})$, and $23.77+/-1.874$ (D). The $95 \%$ Confidence Interval was: 0.90 to $1(\mathrm{HL}), 5.07$ to $7.50(\mathrm{P})$, and 23.07 to 24.47 (D). Linear regression was absent between most of the studied parameters, with exception for the correlation between the inclination of the proximal articular surface and the value of $(\mathrm{P} / \mathrm{HL})$, which revealed a Correlation coefficient $(r): 0.958$, and the relevant $p$-value is $<0.00001$ (significant at $p<0.01$ ). Conclusion: This study is in line with prior studies concerning the morphometry and inclination of radial articular surfaces. It has a tremendous value in biomedical science, biomechanical applications and prosthesis synthesis, corrective surgical and orthopedic procedures, anthropology, and forensic sciences.

Key words: Morphometry, Radius, Articular, Proximal, Distal, Elbow, Wrist, Articular, Japan
http://nepjol.info/index.php/AJMS DOI: 10.3126/ajms.v7i5.14973

E-ISSN: 2091-0576

P-ISSN: 2467-9100

\section{INTRODUCTION}

The word radius is Latin for "ray". The radius is named so because the radial bone acts like the radius of a circle. Further, it rotates around the ulna. The radius, also known as the radial bone, is one of the two large bones of the forearm, the other being the ulna. It extends from the lateral side of the elbow to the thumb side of the wrist and runs parallel to the ulna, which exceeds it in length and size. It is a long bone, prism-shaped and slightly curved longitudinally. The radius is part of four joints: the elbow, the wrist, and the proximal and distal radio-ulnar joints. The radius primarily contributes to the wrist joint, while the ulna is the major contributor to the elbow joint, the radius primarily contributes to the wrist joint. ${ }^{1,2}$

In tetrapod vertebrates, the structure of radius is almost universal. However, it may be fused with the ulna in some 
mammals (including horses) and reduced or modified in animals with flippers or vestigial forelimbs. Even though, in the majority of tetrapods, it represents the main weightbearing bone in the distalportion of the forelimb.,

The radius has a body and two extremities. The proximal part consists of a head, a neck, and a tuberosity. The radial head is a short non-symmetrical cylinder, which bears articular surfaces for the humerus (radio-capitellar joint), and the ulna (proximal radio-ulnar joint). The body of the radius bears the sharp interosseous border, while the distal part is roughly quadrilateral in shape, bearing articular surfaces for the ulna (distal radio-ulnar joint), scaphoid and lunate bones (radio-carpal joint). The distal end of the radius forms two palpable points, the styloid process (laterally) and Lister's tubercle (medially). ${ }^{5}$

At the level of the wrist joint, the carpal articular surface is triangular, concave, smooth, and divided by a slight antero-posterior ridge into two parts, for articulation with the scaphoid (laterally) and the lunate (medially). On the other hand, the ulnar articular surface, is called the ulnar notch, also known as the sigmoid cavity. These two articular surfaces are separated by a prominent ridge, to which the base of the triangular articular disk is attached; this disk separates the wrist-joint from the distal radioulnar articulation. ${ }^{2,5}$

The body (shaft) of the radius is prism-like, slightly curved (convex laterally), and it is narrower above than below. It has three borders (including the interosseous border) and three surfaces. The interosseous border (crest), begins above, at the back part of the tuberosity, and its upper part is rounded and indistinct; it becomes sharp and prominent as it descends, and at its lower part divides into two ridges which are continued to the anterior and posterior margins of the ulnar notch., 2,6

Developmentally, the radius is ossified with three centers located at: the shaft, and the two extremities of the radius. Ossification of the shaft appears nearer to the center of the bone, during the $8^{\text {th }}$ week of fetal life. The ossification center of the distal end, appears 9-26 months of age, while the proximal ossification center appears around the $5^{\text {th }}$ year. The upper epiphysis fuses with the radial shaft at the age of 17-18 years, while the lower epiphysis fusion occurs at the age of twenty. An $4^{\text {th }}$ ossification center, might be found in the radial tuberosity, around the $14^{\text {th }}-15^{\text {th }}$ year of life. ${ }^{7,8}$ This ossification process has an effect on bone morphometry, and the inclination of the proximal and distal articular surfaces.

Numerous pathologies can affect the proximal end of radius and its head. These pathologies include subluxation- dislocations, fractures, degenerative diseases, and other less frequent conditions that may result in alteration of joints' mechanics including Osteochondromas, dystrophic calcification, and heterotopic ossification. ${ }^{9,10}$ These conditions may require corrective procedures including radial head resection, prosthesis implantation, and joint arthroplasty. All these corrective procedures, require accurate restoration of joint mechanics and morphometry by mimicking its original in-vitro dimensions, including those of the radial head (i.e. diameter, depth and inclination of articular surfaces, articular surface area, and volume). A good example to clarify the biomechanical disturbances, is the development of subluxation at the inferior radioulnar joint, in some adult patients, following radial head resection. ${ }^{11}$

Specific fractures frequently affect the radius. These include: fracture that involve the radial head with an accompanying dislocation of the distal radio-ulnar joint (Essex-Lopresti fracture. Other fractures may affect the distal part of radius including: Galeazzi fracture, Colles' fracture, Smith's fracture, and Barton's fracture. ${ }^{12,13}$ To summarize, the radius is a vital bone from a biomechanics perspective, and many pathologies will definitely disrupt joints' morphometry andbiomechanics. Hence, it is of utmost importance to study and restore the normality of these parameters, including the articular surfaces' inclination.

\section{MATERIALS AND METHODS}

Materials used included 30 dry specimens of radial bone, a tape measure, two types of Vernier (analogue and electronic), andan electronic inclinometer. The bony specimens belong to 30 adult deceased individuals of the Japanese population. These specimens were of unidentified age and gender, and of both limbs (26 right, and 4 left).

Measurement were taken at the Anatomical specimens' unit at the laboratories of the department of Anatomy and Cellular Biology, and two anatomists accurately recorded each morphometric parameter.

A standard stainless-steel electronic Vernier micrometer gauge tool (UPC number 814870023454), was used to measure five dimensional parameters including: maximum length of radius $(\mathrm{L})$, maximum thickness/diameter $(\mathrm{T})$ at the mid-point $(\mathrm{M})$ of the interosseous border of radius, maximum length of head of radius (HL). The medio-lateral Inclination (Figure 1) of proximal (P) and distal articular surfaces (D), the inclinations (P and $D)$ were measured in relation to the mid-point of the interosseous border. The mid-point $(M)$ was oriented vertically in a 3-dimensioal (3D) way to the interosseous border. Further, a reference point 
was required for each $\mathrm{P}$ and $\mathrm{D}$ to correctly measure the $3 \mathrm{D}$ medio-lateral inclination of proximal and distal articular surfaces respectively. Additionally, a derived parameter included P/HL, which was calculated and later correlated against $\mathrm{P}$ and $\mathrm{D}$.

In relation to $\mathrm{P}$ calculation, the reference point was in line with the mid-point on the surface of the radial tuberosity, while for $\mathrm{D}$, the reference point was the mid-point of the medial border of Distal end of radius.

The 3D-inclincation of $\mathrm{P}$, was measured by measuring the inclination of a straight line from the center of radial head to the radial head reference point, while the inclination of $\mathrm{D}$ was also measured, by measuring the inclination of a straight line from the styloid process to the distal articular surface reference point. The inclination of each straight line, for both $\mathrm{P}$ and $\mathrm{D}$, was then measured using the electronic inclinometer, against the midpoint of the interosseous border, to give the 3D medio-lateral inclination of both articular surfaces.

The units of measurements were recorded in centimeters $(\mathrm{cm})$ for $\mathrm{L}, \mathrm{T}$, and $\mathrm{HL}$, while in degrees for both $\mathrm{P}$ and $\mathrm{D}$. Measurements of $\mathrm{L}, \mathrm{HL}$, and $\mathrm{T}$ were approximated to the nearest centile, percentile, and $1 / 10^{\text {th }}$ of a percentile respectively. $\mathrm{P}$ and $\mathrm{D}$ were approximated to the nearestangular centile.

During all sorts of measurements, specifically angular (inclination) measurements, the radius was fixed at 90 degrees vertically in relation to the ground. Thereby, avoiding any tilting that may result in faulty Vernier's readings. The Vernier's external jaws were utilized to calculate the morphometric parameters: T and HL.

Two anatomists repeated each measurement to avoid manmade errors and biases, and when their measurements were debatable, a $3^{\text {rd }}$ measurement was taken to resolve the recorded numerical disparity. The recorded final readings (Table 1) represent the average readings for each morphometric parameter, as recorded accurately using the electronic Vernier. Statistical data were calculated using the Statistical Package for Social Sciences (SPSS version 20.0), Microsoft Excel 2016, and Shodor-Interactivate software. ${ }^{14}$

Additionally, a detailed and systematic literature review, was conducted (12 $2^{\text {th }}$ of April, $2016-15^{\text {th }}$ of May, 2016), concerning the osteology of radius, its articular surfaces and their inclination, and previous studies on the topic. Specific and pre-determined keywords (including MeSH), were used across medical and paramedical databases: PubMed, The Cochrane Library, OpenGrey, and Google Scholar. This search methodology was aiming to extract the most relevant and up-to-date literature material on the topics, which were published in professional and high-impact journals in the past 5 years (2012-2016). However, other literature materials and papers, were also considered when found relevant, necessary, and of high level-of-evidence (judgment done based on critical analysis of each paper).

Total number of relevant papers, which were initially mapped were 40. The papers and textbooks, were later filtered by reading the paper title, abstract, and main manuscript text. Duplicate papers were also excluded. Accordingly, only 15 reference materials which are relevant to the topic and of high evidence, were used in the citation of this paper.

\section{RESULTS AND DISCUSSION}

Statistical analyses (Table 2), are also graphically presented as a box-whisker plot chart (Figure 2). The mean values are: $23.22 \mathrm{~cm}(\mathrm{~L}), 1.433 \mathrm{~cm}(\mathrm{~T}), 0.95 \mathrm{~cm}(\mathrm{HL}), 6.283$ degrees (P), 23.766 degrees (D), and 6.67 degrees/cm (P/HL).

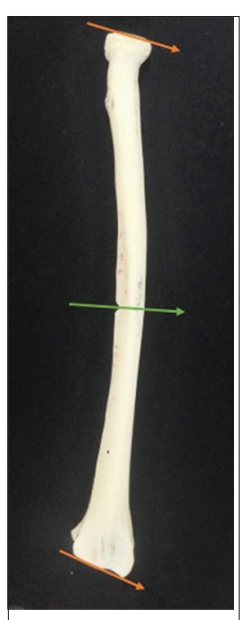

Figure 1: Medio-lateral inclination of proximal and distal articular surfaces (brown arrows) of radius

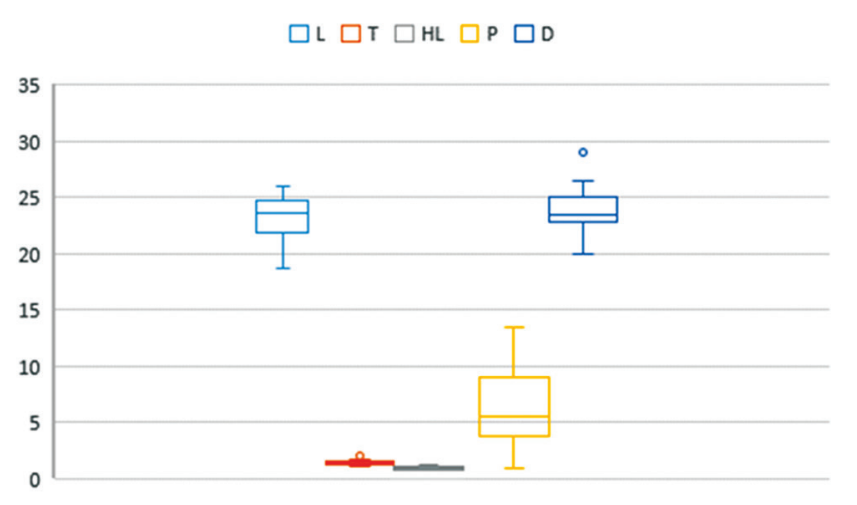

Figure 2: Box-whisker plot 


\begin{tabular}{|c|c|c|c|c|c|c|c|c|c|}
\hline No. & & Limb & $\begin{array}{l}\mathrm{L} \\
(\mathrm{cm})\end{array}$ & $\begin{array}{c}\mathrm{T} \\
(\mathrm{cm})\end{array}$ & $\begin{array}{l}\mathrm{HL} \\
(\mathrm{cm})\end{array}$ & $\begin{array}{c}\mathrm{P} \\
\text { (degrees) }\end{array}$ & $\begin{array}{c}M \\
\text { (degrees) }\end{array}$ & $\begin{array}{c}D \\
\text { (degrees) }\end{array}$ & $\begin{array}{c}\mathrm{P} / \mathrm{HL} \\
\text { (cm/degrees) }\end{array}$ \\
\hline 1. & & Lt. & 25 & 1.309 & 0.96 & 4 & $\begin{array}{l}\text { Reference Point } \\
\text { (i.e. Zero degree) }\end{array}$ & 23.5 & 4.17 \\
\hline 2. & & Rt. & 23.9 & 1.621 & 1.08 & 5 & & 24 & 4.63 \\
\hline 3. & & Rt. & 21.8 & 1.364 & 0.75 & 8.5 & & 24 & 11.33 \\
\hline 4. & & Lt. & 26.1 & 1.164 & 1.01 & 1 & & 22.5 & 0.99 \\
\hline 5. & & Rt. & 24.7 & 1.596 & 1.03 & 13 & & 24.5 & 12.62 \\
\hline 6. & & Rt. & 21.9 & 1.292 & 0.73 & 4.5 & & 23 & 6.16 \\
\hline 7. & & Rt. & 23.4 & 1.489 & 1.11 & 7.5 & & 23.5 & 6.76 \\
\hline 8. & & Rt. & 24.4 & 1.481 & 0.93 & 5 & & 23 & 5.38 \\
\hline 9. & & Rt. & 25.4 & 1.548 & 0.95 & 6.5 & & 25.5 & 6.84 \\
\hline 10. & & Rt. & 22.7 & 1.529 & 1.06 & 8 & & 22.5 & 7.55 \\
\hline 11. & & Rt. & 24.7 & 1.759 & 1.22 & 10 & & 24 & 8.2 \\
\hline 12. & & Rt. & 23.2 & 1.555 & 0.85 & 6 & & 23 & 7.06 \\
\hline 13. & & Lt. & 24.8 & 1.599 & 1.28 & 5 & & 21 & 3.91 \\
\hline 14. & & Rt. & 25.6 & 1.806 & 1.07 & 5 & & 23.5 & 4.67 \\
\hline 15. & & Rt. & 24.8 & 1.317 & 0.98 & 4.5 & & 26.5 & 4.59 \\
\hline 16. & & Rt. & 21.8 & 1.268 & 0.83 & 8 & & 20 & 9.64 \\
\hline 17. & & Rt. & 22.9 & 1.281 & 0.92 & 5 & & 20.5 & 5.44 \\
\hline 18. & & Rt. & 24 & 1.359 & 0.95 & 9 & & 23.5 & 9.47 \\
\hline 19. & & Rt. & 20.1 & 1.446 & 0.85 & 2.5 & & 24 & 2.94 \\
\hline 20. & & Rt. & 23.4 & 1.527 & 0.85 & 1 & & 25 & 1.18 \\
\hline 21. & & Rt. & 24.3 & 1.207 & 1.10 & 9 & & 25 & 8.18 \\
\hline 22. & & Rt. & 23.8 & 1.379 & 0.97 & 3 & & 24.5 & 3.09 \\
\hline 23. & & Rt. & 22.6 & 1.278 & 0.98 & 2.5 & & 21.5 & 2.55 \\
\hline 24. & & Rt. & 25 & 2.013 & 0.94 & 3 & & 29 & 3.09 \\
\hline 25. & & Rt. & 19.9 & 1.471 & 0.92 & 13.5 & & 22.5 & 14.67 \\
\hline 26. & & Rt. & 19.9 & 1.260 & 0.70 & 3.5 & & 23 & 5 \\
\hline 27. & & Rt. & 18.7 & 1.255 & 0.77 & 6 & & 26 & 7.79 \\
\hline 28. & & Lt. & 23.8 & 1.340 & 0.97 & 9 & & 26.5 & 9.28 \\
\hline 29. & & Rt. & 20.7 & 1.104 & 0.83 & 10 & & 23 & 12.05 \\
\hline 30. & & Rt. & 23.4 & 1.379 & 0.91 & 10 & & 25 & 10.99 \\
\hline \multirow{3}{*}{$\begin{array}{l}31 . \\
\text { Mean }\end{array}$} & & & & & & & & & \\
\hline & 26 & 4 & 23.23 & 1.433 & 0.95 & 6.283 & 0 & 23.77 & 6.67 \\
\hline & Rt. & Lt. & & & & & & & \\
\hline
\end{tabular}

The standard deviation (s) were: $1.89 \mathrm{~cm}(\mathrm{~L}), 0.2 \mathrm{~cm}(\mathrm{~T})$, $0.135 \mathrm{~cm}$ (HL), 3.253 degrees (P), and 1.874 degrees (D).

The $95 \%$ confidence intervals $(95 \% \mathrm{CI})$ were: 22.5 to $23.9 \mathrm{~cm} \mathrm{(L),} 1.355$ to $1.505 \mathrm{~cm}$ (T), 0.90 to $1 \mathrm{~cm}$ (HL), 5.07 to 7.50 degrees $(\mathrm{P})$, and 23.07 to 24.47 degrees (D). It is very important to mention that the results of this paper concerning the inclination of the distal articular surface (D), goes in line with another study from 1984. Solgaard (1984), in a sample of 57 normal radiographs of the wrist, found that the radial inclination, was of an average of 23 degrees. ${ }^{15}$

Correlation and linear regression analysis was done for: $\mathrm{P}$ vs. D (Figure 3), L vs. P (Figure 4), L vs. D (Figure 5), HL vs. P(Figure 6), Pvs. P/HL (Figure 7), and D vs. P/HL (Figure 8). There was no significant correlation, for most of these correlations, even at $p<0.10$, with an exception of a significant correlation of $\mathrm{P}$ vs. $\mathrm{P} / \mathrm{HL}$, the Correlation coefficient $(r)$ was 0.958 , and the corresponding $p$-value was $<0.00001$ (significant at $p<0.01$ ). Further, multiple linear regression

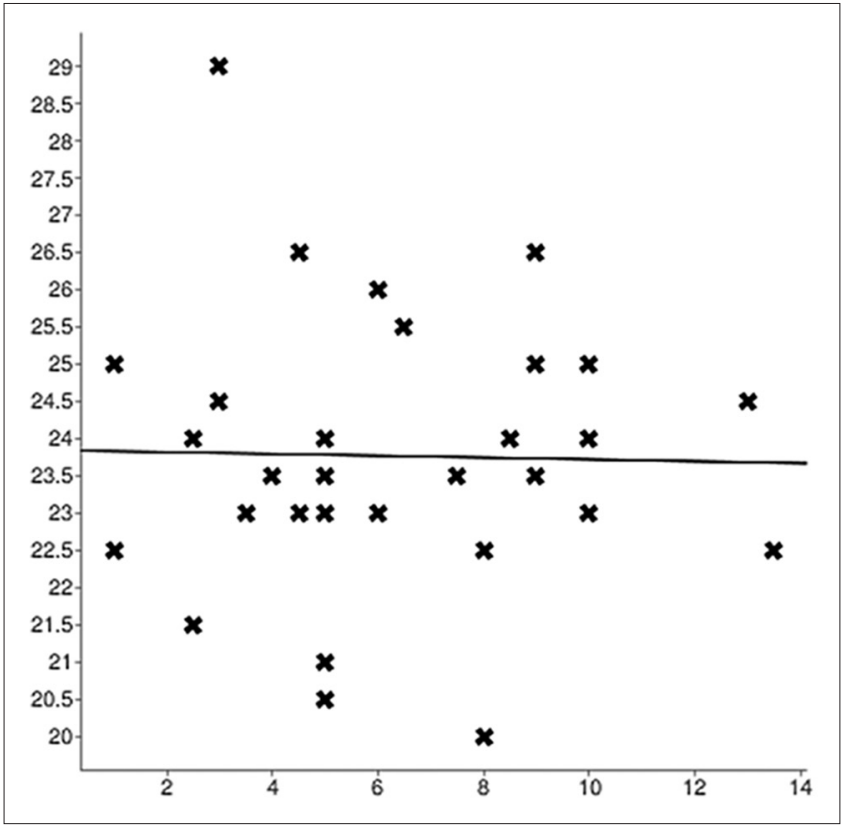

Figure 3: Linear regression of Proximal (P) vs. Distal (D) articular surface inclinations 


\begin{tabular}{|c|c|c|c|c|c|}
\hline Statistical parameters & L (cm) & $\mathrm{T}(\mathrm{cm})$ & HL (cm) & $\mathrm{P}$ (degrees) & D (degrees) \\
\hline Sample size & 30 & 30 & 30 & 30 & 30 \\
\hline Mean $(\bar{x})$ & 23.23 & 1.43 & 0.95 & 6.283 & 23.766 \\
\hline Median & 23.6 & 1.379 & 0.95 & 5.5 & 23.5 \\
\hline Mode & 23.4 & 1.379 & 0.85 & 5 & 23 \\
\hline Lowest value & 18.7 & 1.104 & 0.7 & 1 & 20 \\
\hline Highest value & 26.1 & 2.013 & 1.28 & 13.5 & 29 \\
\hline Range & 7.4 & 0.909 & 0.058 & 12.5 & 9 \\
\hline Interquartile range & 2.85 & 0.269 & 0.188 & 5.125 & 2.125 \\
\hline First quartile & 21.88 & 1.280 & 0.85 & 3.875 & 22.875 \\
\hline Third quartile & 24.73 & 1.549 & 1.038 & 9 & 25 \\
\hline Variance (s2) & 3.58 & 0.04 & 0.018 & 10.581 & 3.513 \\
\hline Standard deviation (s) & 1.89 & 0.20 & 0.135 & 3.253 & 1.874 \\
\hline Quartile deviation & 1.43 & 0.135 & 0.094 & 2.562 & 1.063 \\
\hline $\begin{array}{l}\text { Mean absolute } \\
\text { deviation (MAD) }\end{array}$ & 1.5 & 0.158 & 0.101 & 2.688 & 1.384 \\
\hline \multicolumn{6}{|l|}{ Confidence Interval (Cl) } \\
\hline $90 \%$ & 22.6 to 23.8 & 1.368 to 1.492 & 0.91 to 0.99 & 5.27 to 7.29 & 23.18 to 24.35 \\
\hline $95 \%$ & 22.5 to 23.9 & 1.355 to 1.505 & 0.90 to 1 & 5.07 to 7.50 & 23.07 to 24.47 \\
\hline $99 \%$ & 22.3 to 24.2 & 1.329 to 1.531 & 0.88 to 1.02 & 4.65 to 7.92 & 22.82 to 24.71 \\
\hline Statistical Correlation \& Linear & \multicolumn{5}{|c|}{ Correlation coefficient $(r):-0.0213$} \\
\hline Regression of $\mathrm{P}$ vs. D & \multicolumn{5}{|c|}{ The $p$ values 0.912 . The result is not significant at $p<0.01$. } \\
\hline Statistical Correlation \& Linear & \multicolumn{5}{|c|}{ Correlation coefficient $(r):-0.152$} \\
\hline Regression of $L$ vs. $P$ & \multicolumn{5}{|c|}{ The $p$ values 0.423 . The result is not significant at $p<0.10$} \\
\hline Statistical Correlation \& Linear & \multicolumn{5}{|c|}{ Correlation coefficient $(r): 0.1896$} \\
\hline Regression of $L$ vs. D & \multicolumn{5}{|c|}{ The $p$ values 0.316 . The result is not significant at $p<0.10$} \\
\hline Statistical Correlation \& Linear & \multicolumn{5}{|c|}{ Correlation coefficient $(r): 0.139$} \\
\hline Regression of HL vs. P & \multicolumn{5}{|c|}{ The $p$ values 0.463 . The result is not significant at $p<0.10$} \\
\hline Statistical Correlation \& Linear & \multicolumn{5}{|c|}{ Correlation coefficient $(r): 0.958$} \\
\hline Regression of $\mathrm{P}$ vs. $\mathrm{P} / \mathrm{HL}$ & \multicolumn{5}{|c|}{ The $p$ values $<0.00001$. The result is significant at $p<0.01$} \\
\hline Statistical Correlation \& Linear & \multicolumn{5}{|c|}{ Correlation coefficient $(r):-0.0413$} \\
\hline Regression of D vs. P/HL & \multicolumn{5}{|c|}{ The $p$ values 0.8296 . The result is not significant at $p<0.10$} \\
\hline Multiple Linear Regression of & \multicolumn{5}{|c|}{ Residual Sum of Squares $(r s s)=0.521$} \\
\hline$P, D$, vs. HL & \multicolumn{5}{|c|}{ Coefficient of Determination $\left(R^{2}\right)=0.0214$} \\
\hline
\end{tabular}

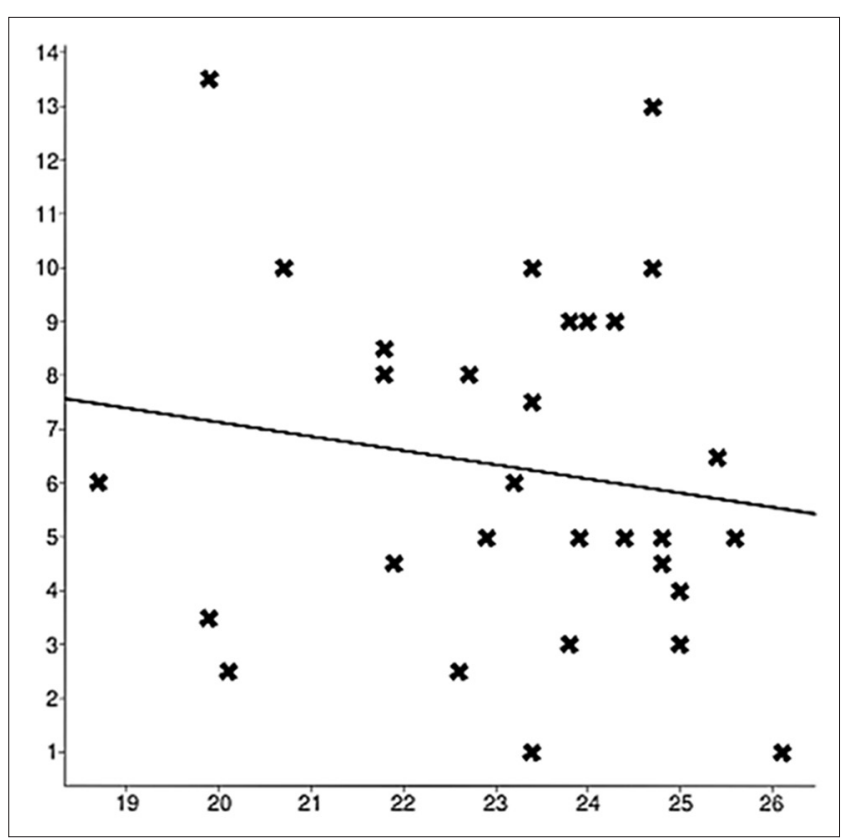

Figure 4: Linear regression of Length of radius $(L)$ versus proximal $(P)$ articular surface inclination

data of P, D, versus HL, revealed a Residual Sum of Squares $(r s s)=0.521$ and Coefficient of Determination $\left(R^{2}\right)=0.0214$.
To summarize, these morphometry parameters can be used for practical application in: anthropology, comparative Anatomy and evolutionary Biology, prosthesis synthesis (radial head and Radiocapitellar joint), biomedical and biomechanical applications, reference values for orthopedic and arthroscopic surgery, rheumatology and degenerative Medicine, forensic sciences, and Anthropometrics.

\section{CONCLUSIONS}

The inclination of the articular surfaces of the radius, is of prime value in biomedical applications. These morphometric parameters were identified, explored and studied, and statistically analyzed. Surprisingly, there was no correlation between most of the studied parameters, including the inclination values of proximal and distal articular surfaces. However, the results in relation to the degree of inclination of the distal articular surface, was in concordance with data from another paper dating back to 1984. Both studies concluded that the medio-lateral inclination was approximately 23 degrees. 


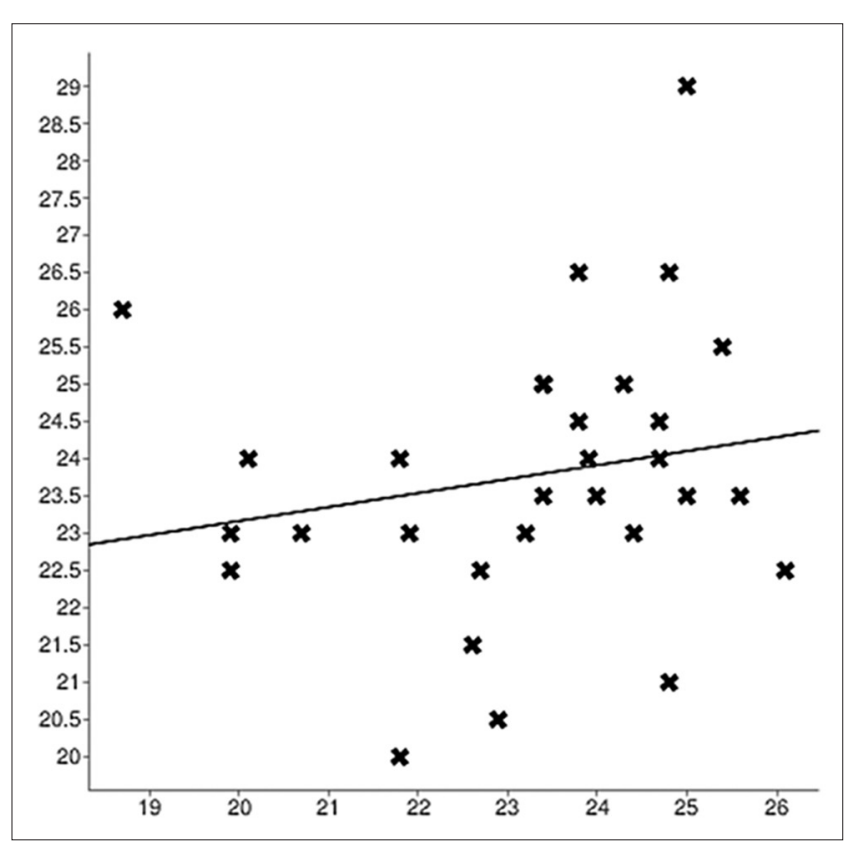

Figure 5: Linear regression of Length (L) vs. Distal (D) articular surface inclination

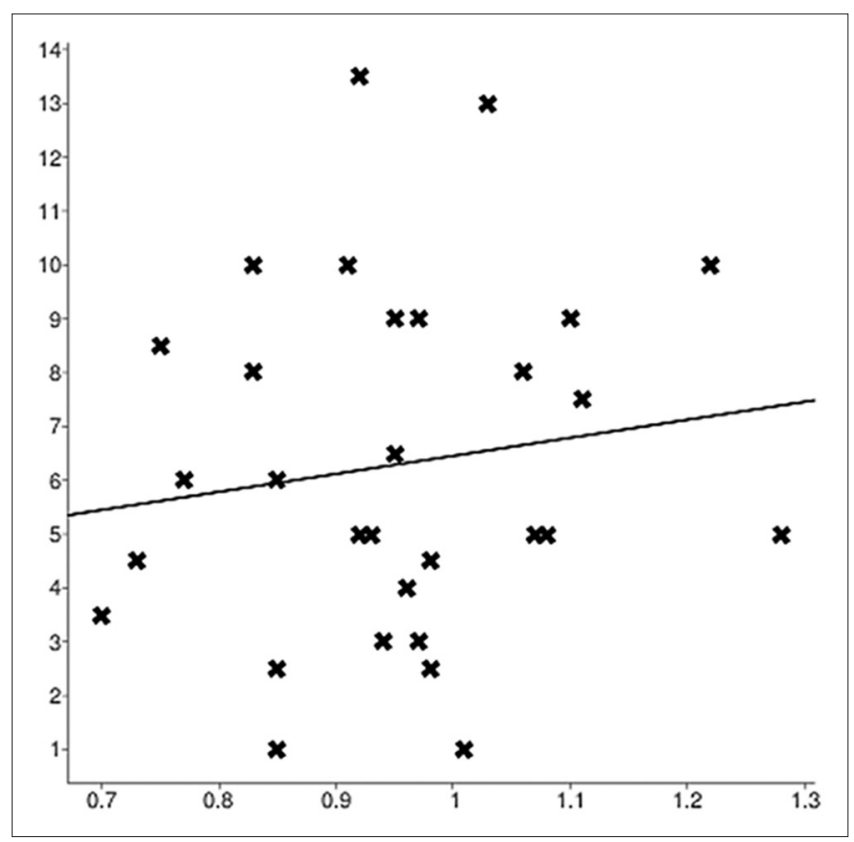

Figure 6: Linear regression of Head length $(\mathrm{HL})$ of radius versus proximal $(P)$ articular surface inclination

There are many conditions that may affect the articular surfaces and their inclination, including: fractures, subluxation-dislocations, degenerative joint disease, tumorous pathologies, dystrophic changes, and abnormal deposits. All these can significantly alter the biomechanics, at the levels of: elbow, wrist, proximal and distal radio-ulnar joints. Accordingly, this paper serves the purpose to identify the normal values (standardization) of inclination indices, required for

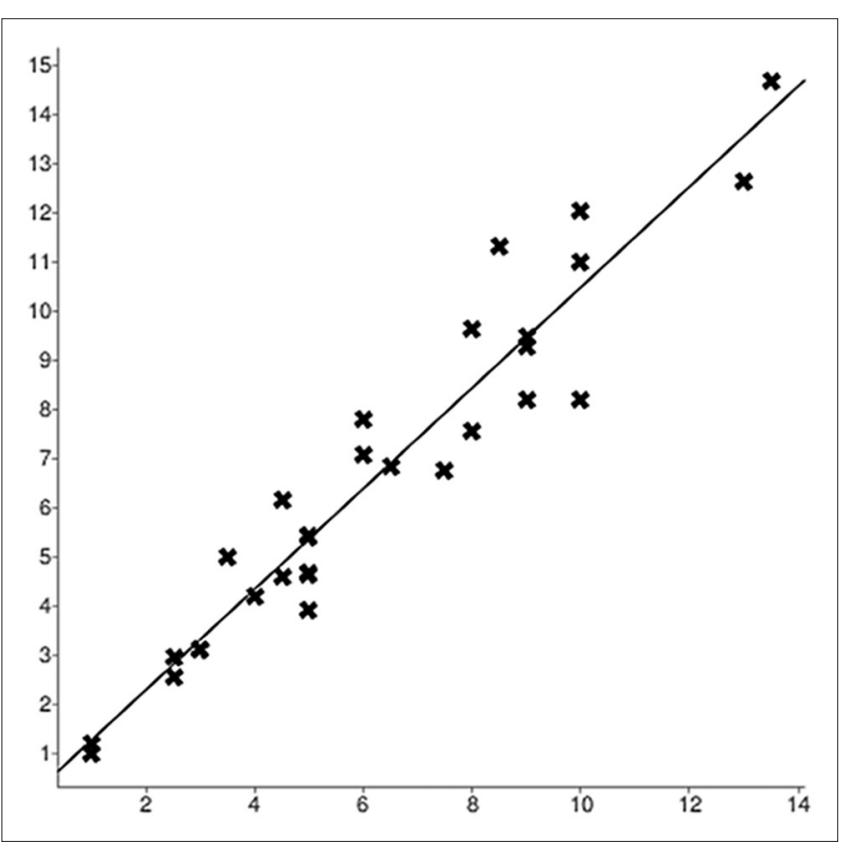

Figure 7: Linear regression of Proximal $(P)$ articular surface inclination vs. $\mathrm{P} / \mathrm{HL}$

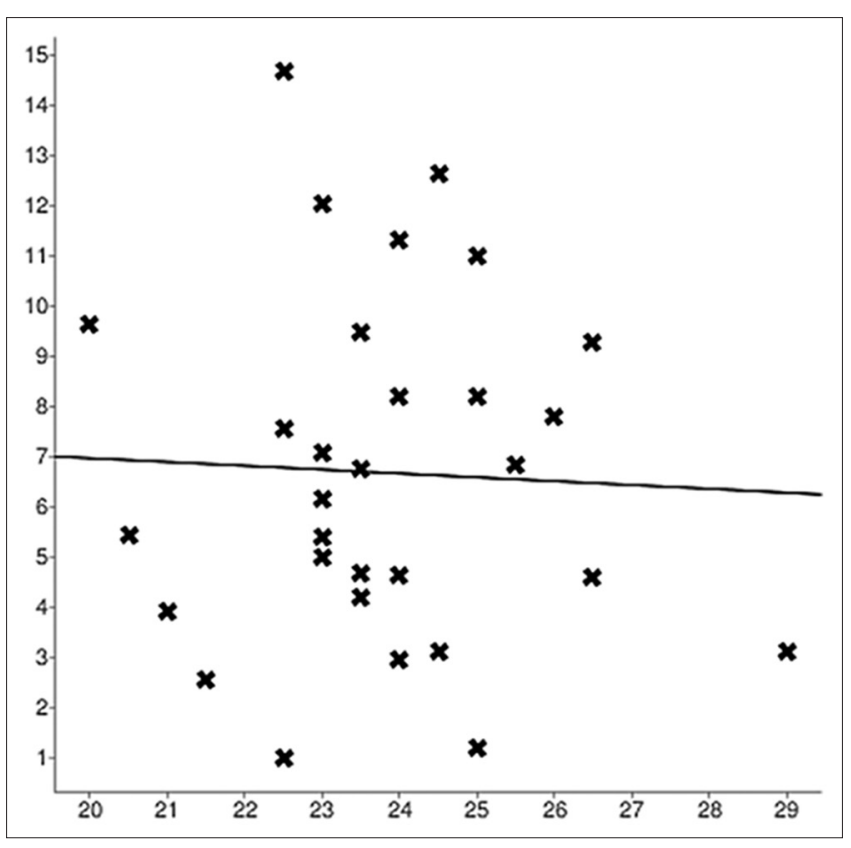

Figure 8: Linear regression of Distal (D) articular surface inclination vs. $\mathrm{P} / \mathrm{HL}$

restorative procedures for the previously mention pathologic conditions.

\section{LIMITATIONS}

1. Sample size is moderately small.

2. This study was limited only to the Japanese ethnicity, and inter-racial variabilities is to be further explored and analyzed. 
3. The mid-point of the interosseous border, was difficult to localize, some of these borders had their upper (superior) and lower (inferior) limits blurred.

4. This study is purely an osteology-based one. Radiologic data (including $\mathrm{X}$-rays) are further required for cross reference purposes.

5. The inclination of the proximal and distal articular surfaces, was studied in medio-lateral direction only. The antero-posterior inclination is also to be studied, with relevant correlation with the medio-lateral inclination.

\section{ACKNOWLDGMENTS}

- Acknowledgment and gratitude to those who donated their bodies to the Anatomy department. These donations made this Anatomical study possible, to allow further development and progress in service of Humanity.

- Much appreciation to Mohammed-Lutfi Al-Imam, for his insightful remarks on choosing the using the correct mathematical forumlas and equations for this paper calculations. Mr. Al-Imam is a consultant mechanical engineer.

- Appreciation and gratitude to Miss Nada Mons hid for her help to provide the bony specimens for this study. Ms. Nada is an employee at the Anatomical specimen's laboratory, at the department of Anatomy and cellular Biology.

\section{REFERENCES}

1. Marieb E, Mallatt $J$ and Wilhelm P. Human Anatomy ( $5^{\text {th }}$ ed.), San Francisco, CA: Pearson Benjamin Cummings, 2008: p. 188.
2. Drake R, Vogl AW and Mitchell AW. Gray's anatomy for students. Elsevier Health Sciences; 2014.

3. Kardong KV. Vertebrates: comparative anatomy, function, evolution. Boston: McGraw-Hill; 2006.

4. Hyman LH. Hyman's comparative vertebrate anatomy. University of Chicago Press; 1992.

5. Clemente, Carmine D. Anatomy: A Regional Atlas of the Human Body ( $5^{\text {th }}$ ed.), Philadelphia, PA: Lippincott Williams \& Wilkins, 2007.

6. Waugh A and Grant A. Ross and Wilson anatomy and physiology in health and illness. Elsevier Health Sciences; 2014.

7. deRoo T and Schröder HJ. Pocket atlas of skeletal age. Springer Science \& Business Media; 2012.

8. Gilsanz V and Ratib O. Indicators of Skeletal Maturity in Children and Adolescents. InHand Bone Age 2012 (pp. 11-19). Springer Berlin Heidelberg.

9. Taylor TK and O'connor BT. The effect upon the inferior radioulnar joint of excision of the head of the radius in adults. Journal of Bone \& Joint Surgery, British Volume. 1964;46(1):83-88.

10. Burkhart KJ, Nowak TE, Kim YJ, Rommens PM and Müller LP. Anatomic fit of six different radial head plates: comparison of precontoured low-profile radial head plates. The Journal of hand surgery 2011; 36(4):617-624.

11. Guitton TG, van der Werf HJ and Ring D. Quantitative threedimensional computed tomography measurement of radial head fractures. Journal of Shoulder and Elbow Surgery 2010;19(7):973-977.

12. Sivananthan S, Sherry E, Warnke P, Miller MD, editors. Mercer's Textbook of Orthopaedics and Trauma Tenth edition. CRC Press; 2012.

13. Bentley G, editor. European Surgical Orthopaedics and Traumatology: The EFORT Textbook. Springer Berlin Heidelberg; 2014.

14. Available at: http://www.shodor.org/interactivate/activities/. Accessed May 8, 2016.

15. Solgaard S. Angle of inclination of the articular surface of the distal radius. Der Radiologe 1984;24(7):346-348.

\section{Authors Contribution:}

AA is the sole author of this paper, he was responsible for Bony Specimens acquisition and analysis, Data collection, Data analysis, Drafting the manuscript, Carrying out the literature review, Editing the final manuscript paper.

Source of Support: Nil, Conflict of Interest: None declared. 